\title{
Energia estática na atmosfera sobre o Nordeste do Brasil: Fluxo e variação sazonal de energia
}

\author{
Ranyére S. Nóbrega ${ }^{1}$, Enio P. Souza ${ }^{2}$ \& Enilson P. Cavalcanti ${ }^{2}$
}

\begin{abstract}
RESUMO
Neste trabalho estudou-se a variação sazonal de energia estática da atmosfera sobre a região Nordeste do Brasil (NEB). Foram utilizados dados climatológicos de Reanálises do "National Center for Environmental Prediction - National Center for Atmospheric Research" (NCEP-NCAR) referentes à média do período de 12 anos (1982 a 1993), em 17 níveis de pressão. Analisaram-se os perfis verticais médios das energias estáticas seca, úmida e saturada, assim como os campos do fluxo e da divergência do fluxo das respectivas energias, para os meses de março, junho, setembro e dezembro. Os resultados revelam que os valores de energia total indicam diferença quase insignificante mês a mês; entretanto, as diferenças entre as energias úmidas e saturadas são significativas e conduzem a interpretações úteis. A convergência e a divergência de massa, que são entendidas como efeitos dinâmicos, são os principais responsáveis para que ocorra a precipitação, e o que determina a possibilidade de convecção sobre a região é a quantidade de energia de inibição convectiva. A atmosfera sobre o NEB exporta vapor d'água durante os meses secos e o importa nos meses chuvosos.
\end{abstract}

Palavras-chave: CAPE, instabilidade, precipitação

\section{Static energy in the atmosphere over Northeast Brazil: Flow and seasonal variation of energy}

\begin{abstract}
In this work the seasonal variation of static energy of the atmosphere over Brazil's Northeast region (NEB) was studied. Climatological data of "Reanálises" of the National Center for Environmental Prediction - National Center for Atmospheric Research (NCEP-NCAR) referring to average of 12 years (1982 to 1993) in 17 pressure levels were used. The average vertical profiles of the dry, moist and saturated static energies, as well as the field of the flow and of the divergence of the flow of the respective energies were analyzed, for the months of March, June, September and December. The results reveal that the values of total energy indicate almost insignificant difference month by month; however, the differences among moist and saturated energies are significant and lead to useful interpretations. The convergence and the mass divergence, which are understood as dynamic effects, are responsible for the occurrence of precipitation, and what determines the convection possibility over the region is the inhibition convective energy quantity. The atmosphere over NEB exports water vapor during dry months and imports in the rainy months.
\end{abstract}

Key words: CAPE, instability, rainfall 


\section{INTRODUÇÃO}

O Nordeste Brasileiro (NEB) está submetido a adversidades climáticas que afetam a precipitação sobre a região e estão relacionadas à variabilidade, tanto espacial quanto temporal, da precipitação sobre o NEB. Tal variabilidade está associada a diferentes sistemas atmosféricos da circulação geral que atuam sobre a região em épocas distintas do ano, a fenômenos atmosféricos e oceânicos que ocorrem em outras partes do globo, como os eventos ENOS (El Niño/Oscilação Sul) sobre o Pacífico Tropical, bem como à ocorrência de anomalias de temperatura da superfície do mar (TSM) sobre o Atlântico Tropical.

Segundo Strang (1972) todo o litoral norte e leste do NEB e a parte noroeste, recebem pluviosidade média anual acima de $1.200 \mathrm{~mm}$, chegando a atingir $2.000 \mathrm{~mm}$ em alguns pontos do litoral sul, enquanto em seu interior chega a atingir cerca de $500 \mathrm{~mm}$. A variação temporal da precipitação também foi citada por Rao \& Brito (1984): por exemplo, o ano de 1974 apresentou um desvio acima da média de 120\% enquanto no ano de 1980 este desvio foi de 40\% abaixo da média. Os mecanismos dinâmicos que produzem chuvas no NEB podem ser classificados em mecanismos de grande escala, que são responsáveis por cerca de 30 a $80 \%$ da precipitação observada, dependendo do local, e mecanismos de meso e micro-escalas, que completam os totais observados. Dentre os mecanismos de grande escala destacam-se os sistemas frontais, vórtices ciclônicos, linhas de instabilidade e a zona de convergência intertropical (ZCIT). Perturbações ondulatórias no campo dos ventos alísios, complexos convectivos e brisas marítima e terrestre, fazem parte da mesoescala, enquanto circulações orográficas e pequenas células convectivas se constituem fenômenos de microescala e escala convectiva (Molion \& Bernardo, 2000). Vários estudos evidenciam a existência de bastante umidade sobre a região, até mesmo em épocas de pouca chuva. Cavalcanti (1986) acredita que a ausência de mecanismos dinâmicos que favoreçam a convecção, pode estar relacionada com as épocas de poucas chuvas. Marques et al. (1983) também estudaram a energética da atmosfera sobre o NEB; entretanto, esses estudos quantificam a energia importada ou exportada da região em diferentes situações mas não detalham o comportamento do transporte de energia nem identificam as suas fontes e sumidouros.

Vários estudos relativos ao balanço de energia na região foram efetuados (Cavalcanti, 1986; Rao et al., 1998). Todos evidenciaram a existência de bastante umidade sobre a área; o que falta, em épocas de pouca chuva, são mecanismos dinâmicos que favoreçam a convecção para a formação de nuvens com capacidade de precipitar. Esses estudos quantificam a energia importada ou exportada do NEB em diferentes situações, mas não detalham o comportamento do transporte de energia nem identificam as suas fontes e sumidouros. No presente estudo pretende-se analisar o transporte de energia em diferentes níveis isobáricos e com abrangência externa à própria região de interesse.

Os dados do projeto Reanálises do "National Centers for Environmental Prediction/ National Center for Atmospheric
Research" (NCEP/NCAR) (Kalnay, 1996) possibilitaram este estudo, uma vez que seria extremamente complexo e falho trabalhar com radiossondagens, devido à existência de falhas no espaço e no tempo, verificadas nessas sondagens.

Esse trabalho foi realizado com o objetivo de estudar o transporte de energia estática na atmosfera sobre o NEB, com o propósito de identificar fontes e sumidouros de energia e analisar os mecanismos dinâmicos e a variação sazonal da energia estática sobre o NEB e, também, analisar os aspectos da distribuição média da energia estática e seu respectivo transporte para o Nordeste do Brasil, ao longo do ano.

\section{MATERIAL E MÉTODOS}

A área escolhida para as análises está compreendida entre as latitudes de $20^{\circ} \mathrm{N}$ a $60^{\circ} \mathrm{S}$ e longitudes de $120^{\circ}$ a $10^{\circ} \mathrm{W}$, com ênfase para o NEB. Os meses estudados foram março, junho, setembro e dezembro, nos quais ocorrem os solstícios e equinócios. Foram utilizados os valores médios climatológicos de 12 anos (1982 a 1993) das Reanálises dos "National Centers for Environmental Prediction/National Center for Atmospheric Research" (NCEP/NCAR). Os campos utilizados são temperatura, altura geopotencial, umidade específica e vento (componente zonal e meridional) e estão em 17 níveis de pressão $(1000,925,850,700,600,500$, 400, 300, 250, 200, 150, 100, 70, 50, 30, 20 e $10 \mathrm{hPa})$.

Inicialmente, definem-se as energias estáticas. A energia estática seca é definida na forma:

$$
\mathrm{s}=\mathrm{c}_{\mathrm{p}} \mathrm{T}+\mathrm{gz}
$$

em que:

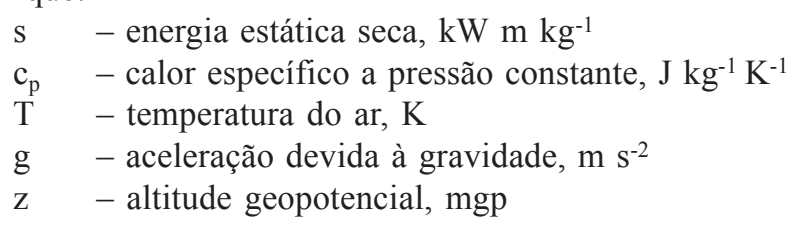

A energia estática úmida é definida na forma:

$$
\mathrm{h}=\mathrm{s}+\mathrm{Lq}
$$

em que:

$$
\begin{array}{ll}
\mathrm{h} & \text { - energia estática úmida, } \mathrm{kW} \mathrm{m} \mathrm{kg} \mathrm{m}^{-1} \\
\mathrm{~L} & \text { - calor latente de condensação, } \mathrm{J} \mathrm{kg}^{-1} \\
\mathrm{q} & \text { - umidade específica, } \mathrm{kg} \mathrm{kg}^{-1}
\end{array}
$$

A energia estática úmida de saturação é definida na forma:

$$
\mathrm{h}_{\mathrm{s}}=\mathrm{s}+\mathrm{Lq}_{\mathrm{s}}
$$

em que:

$\mathrm{h}_{\mathrm{s}} \quad$ - energia estática úmida de saturação, $\mathrm{kW} \mathrm{m} \mathrm{kg-1}$

$\mathrm{q}_{\mathrm{s}} \quad$ - umidade específica de saturação, $\mathrm{kg} \mathrm{kg}^{-1}$ 
Além disso, o vento horizontal é definido como:

$$
\vec{V}=u \vec{i}+v \vec{j}
$$

em que:

$\mathrm{u} \quad$ - componente zonal do vento, $\mathrm{m} \mathrm{s}^{-1}$

$\mathrm{v} \quad$ - componente meridional do vento, $\mathrm{m} \mathrm{s}^{-1}$

Para se avaliar os transportes (zonal e meridional) de energia estática, utilizaram-se as seguintes expressões:

$$
\begin{aligned}
& \vec{F}_{s}=s u \vec{i}+s v \vec{j} \\
& \vec{F}_{h}=h u \vec{i}+h v \vec{j} \\
& \vec{F}=h u \vec{i}+h v \vec{j}
\end{aligned}
$$

em que:

$\overrightarrow{\mathrm{F}}_{\mathrm{s}} \quad-$ Fluxo de energia estática seca, $\mathrm{W} \mathrm{m} \mathrm{kg} \mathrm{m}^{-1}$

$\overrightarrow{\mathrm{F}}_{\mathrm{h}} \quad$ - Fluxo de energia estática úmida, $\mathrm{W} \mathrm{m} \mathrm{kg}^{-1}$

$\overrightarrow{\mathrm{F}}_{\mathrm{hs}} \quad$ - Fluxo de energia estática úmida saturada, $\mathrm{W} \mathrm{m} \mathrm{kg}^{-1}$

Finalmente, a divergência do fluxo de energia estática úmida é dada por

$$
h \cdot \rho \vec{F}_{\mathrm{h}}
$$

em que:

$$
\rho \quad \text { - densidade do ar, } \mathrm{kg} \mathrm{m}^{-3}
$$

Para a análise desses parâmetros, foram construídos: 1) campos do transporte de energia estática úmida; 2) campos das linhas de corrente do fluxo de energia estática úmida sobre o NEB; 3) campos da divergência do fluxo de energia estática úmida; 4) perfis verticais da divergência do fluxo energia estática úmida sobre o NEB; 5) campos da taxa média da precipitação; 6) perfís verticais médios das energias estáticas seca, úmida e saturada, para o NEB; 7) campo da variação sazonal média sobre o NEB, da diferença entre a energia estática úmida saturada e a energia estática úmida.

\section{RESULTADOS E DISCUSSÃO}

A Figura 1 representa a variação mensal do transporte meridional de energia estática úmida sobre o equador terrestre $\left(\phi=0^{\circ}\right)$ no nível de $850 \mathrm{hPa}$. Os valores negativos indicam movimento em direção ao hemisfério sul, e os valores positivos movimentos em direção ao hemisfério norte; isto é útil para verificar o movimento da ZCIT em direção ao NEB. Entre os meses de dezembro a abril, a zona de confluência dos alísios está dirigida para o hemisfério sul, tendo o máximo valor no mês de março, quando a ZCIT está, em sua posição média, mais ao sul, enquanto entre os meses de julho e agosto tem o valor máximo indicando que a posição da ZCIT está mais ao Norte e, consequentemente, mais distante da região Nordeste do Brasil.

As Figuras 2A, 2B, 2C e 2D representam os perfis verti-

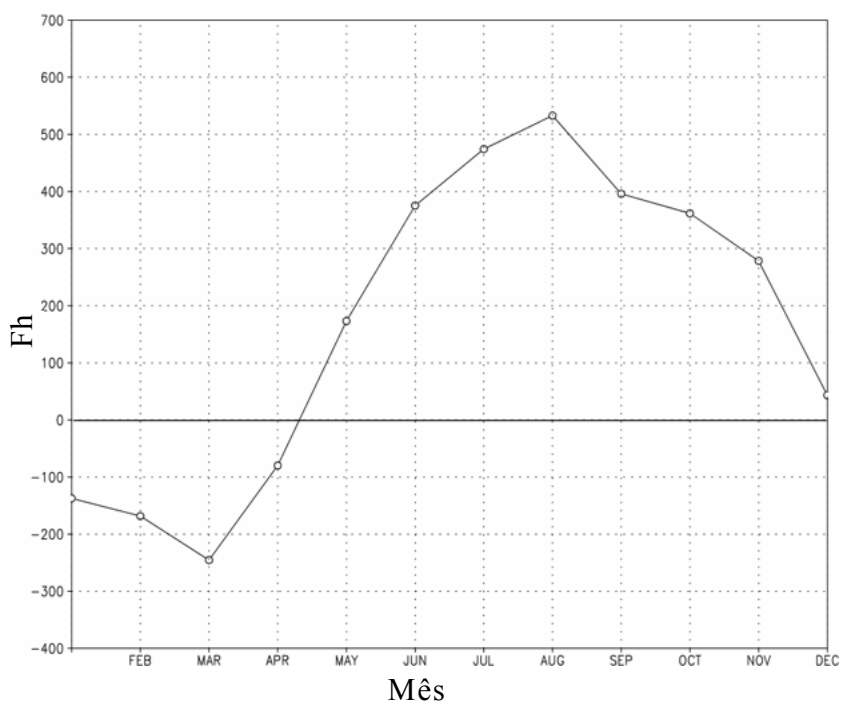

Figura 1. Variação mensal do transporte meridional de energia estática úmida $\left(\mathrm{kW} \mathrm{m} \mathrm{kg}^{-1}\right)$ sobre o equador $\left(\phi=0^{\circ}\right)$ em $850 \mathrm{hPa}$

cais médios de divergência do fluxo de energia estática úmida sobre o NEB, para os meses de março, junho, setembro e dezembro, respectivamente. Os valores positivos indicam divergência e os valores negativos, convergência. Convergência em baixos níveis implica em movimento ascendente do ar, favorecendo a formação de nuvens convectivas; já divergência em baixos níveis é um mecanismo inibidor na formação de nuvens com capacidade convectiva. Observandose as figuras, verifica-se que existe uma condição dinâmica favorável à precipitação nos meses de março e dezembro, pois nesses meses se dá a convergência de energia estática úmida da superfície até aproximadamente o nível de $750 \mathrm{hPa}$; já entre os níveis de 750 a $650 \mathrm{hPa}$ e acima de $400 \mathrm{hPa}$, ocorre divergência. $\mathrm{O}$ motivo de haver condições favoráveis em dezembro está associado ao fato das chuvas iniciarem, na parte leste e sul da região, sua estação chuvosa principal, conforme mostrado adiante.

Em junho e setembro acontece divergência da superfície até aproximadamente $650 \mathrm{hPa}$ e convergência nos níveis mais altos. Devido à continuidade de massa, convergência nos baixos níveis gera movimento vertical ascendente favorecendo, desta forma, o desenvolvimento de nuvens capazes de produzir precipitação, desde que haja umidade suficiente, o que já foi comprovado por Cavalcanti et al. (2002). Esta convergência em baixos níveis favorece a formação de nuvens convectivas. Para os meses secos (junho e setembro), tem-se um efeito dinâmico inibidor da precipitação, com convergência de massa nos níveis acima de $650 \mathrm{hPa}$ e divergência nos níveis abaixo de $650 \mathrm{hPa}$, acarretando um movimento vertical descendente em direção aos níveis mais baixos. Embora seja desfavorável à formação de nuvens convectivas, a umidade presente é suficiente para favorecer o desenvolvimento de nuvens estratiformes, associadas ao período chuvoso da Zona da Mata, que acontece entre junho e setembro, na parte leste do NEB.

As Figuras 3A, 3B, 3C e 3D apresentam a taxa média diária de precipitação, em $\mathrm{mm} \mathrm{d}^{-1}$, para os meses de março, 
A.

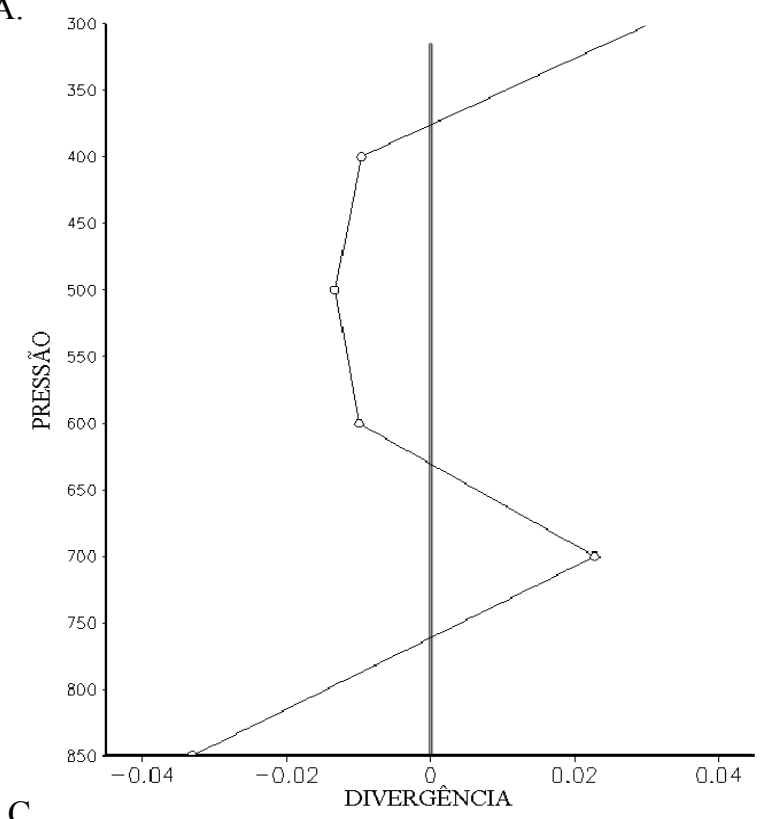

C.

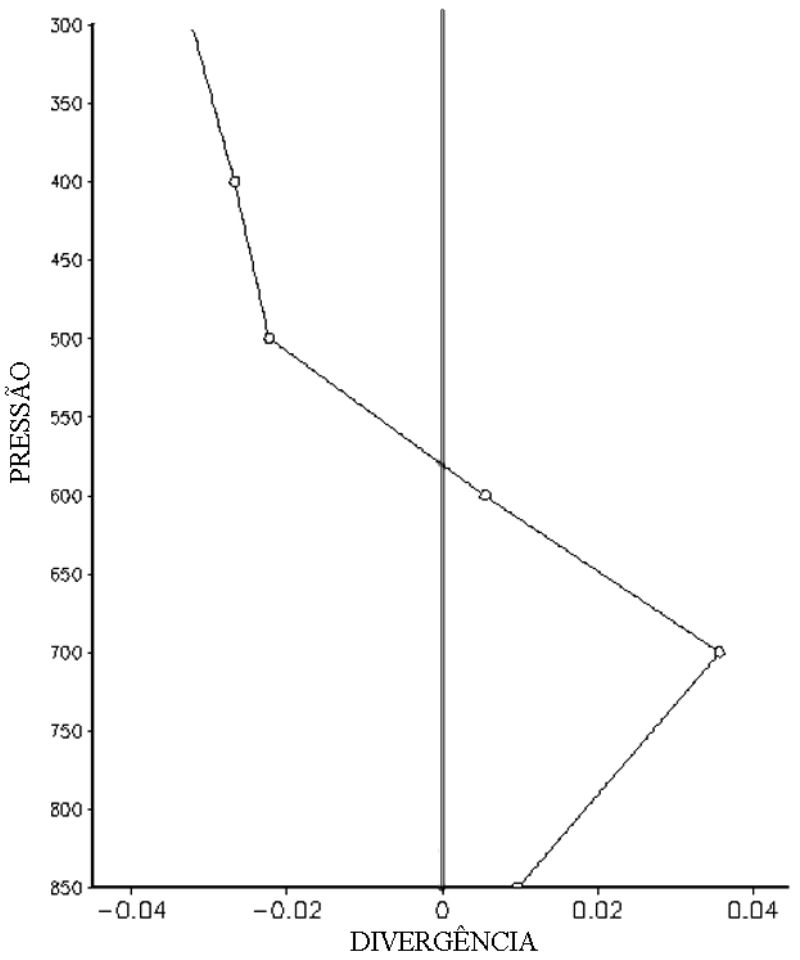

B.

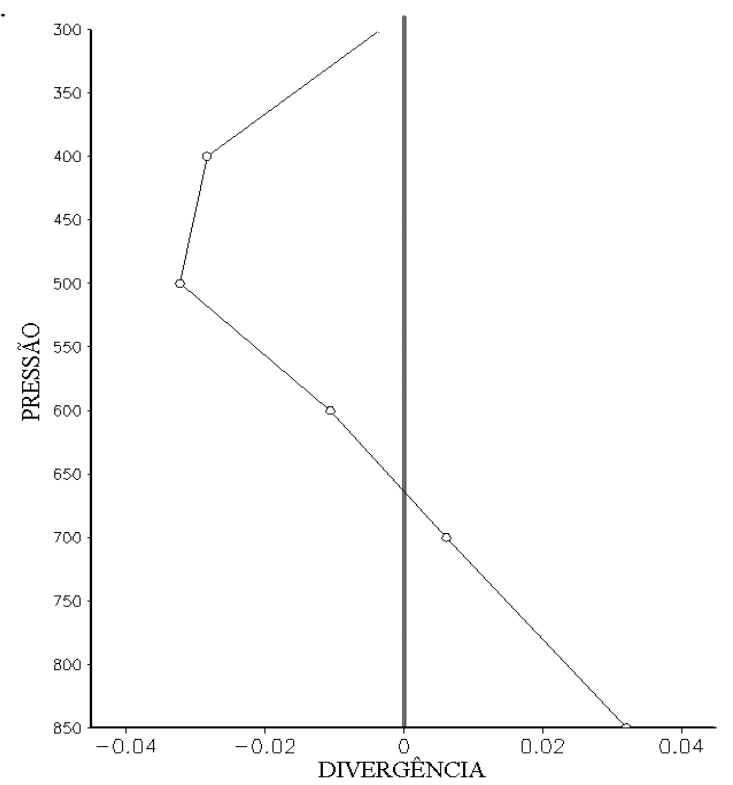

D.

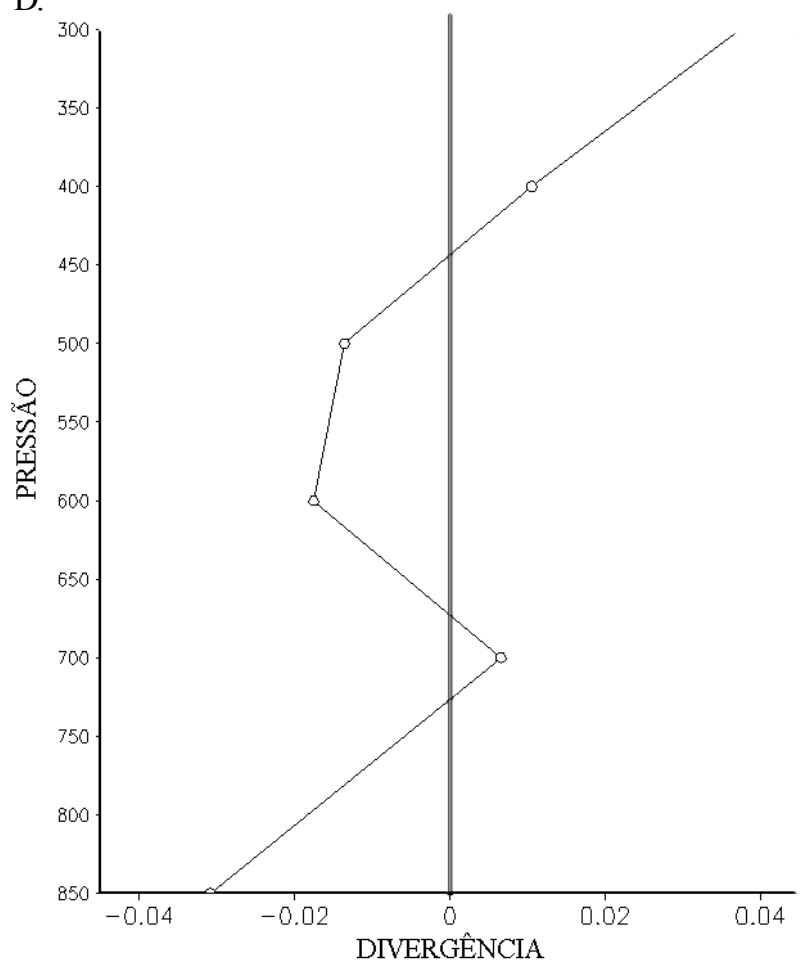

Figura 2. Perfis verticais da divergência do fluxo de energia estática úmida $\left(\mathrm{W} \mathrm{kg}^{-1}\right)$ para os meses: A) março B) junho, C) setembro, D) dezembro

junho, setembro e dezembro, respectivamente. Verifica-se que entre os meses estudados na região NEB o mais chuvoso foi o mês de março, principalmente na parte norte (Figura 4A); já para os meses de junho e setembro (Figuras 4B e 4C, respectivamente) tem-se uma taxa de precipitação menor, comparada com a taxa dos meses mais chuvosos. Não obstante a assinatura do regime chuvoso da Zona da Mata, na parte leste da região é visível, principalmente em junho. Para dezembro (Figura 4D) vê-se a contribuição da precipitação no Brasil Central, que se estende até o oeste do NEB. Esta situação está em concordância com os campos da divergência já discutidos neste trabalho.
As Figuras 4A, 4B, 4C e 4d representam a distribuição vertical média das energias estáticas seca (1), úmida (2) e úmida saturada (3) sobre o NEB ( $\mathrm{kJ} \mathrm{kg}^{-1}$ ) para os meses de março, junho, setembro e dezembro, respectivamente. A energia estática seca não apresenta variações significativas de mês para mês. Com relação à energia estática úmida, esta apresenta coerência com os valores obtidos por Marques et al. (1983), com valores máximos nos baixos e altos níveis da troposfera e mínimos nos níveis médios.

Uma vez que a umidade atmosférica é um parâmetro variável, é também um dos principais causadores da variação na energia estática úmida nos níveis abaixo de $300 \mathrm{hPa}$ na re- 
A

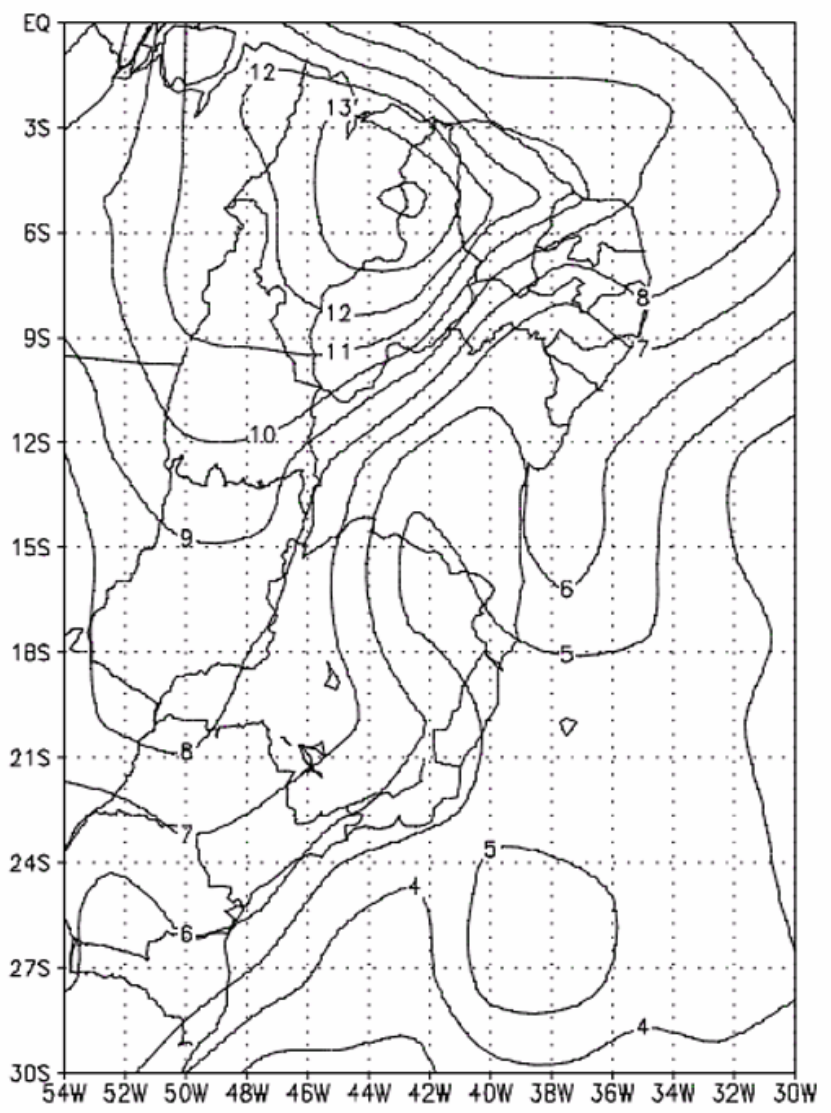

B

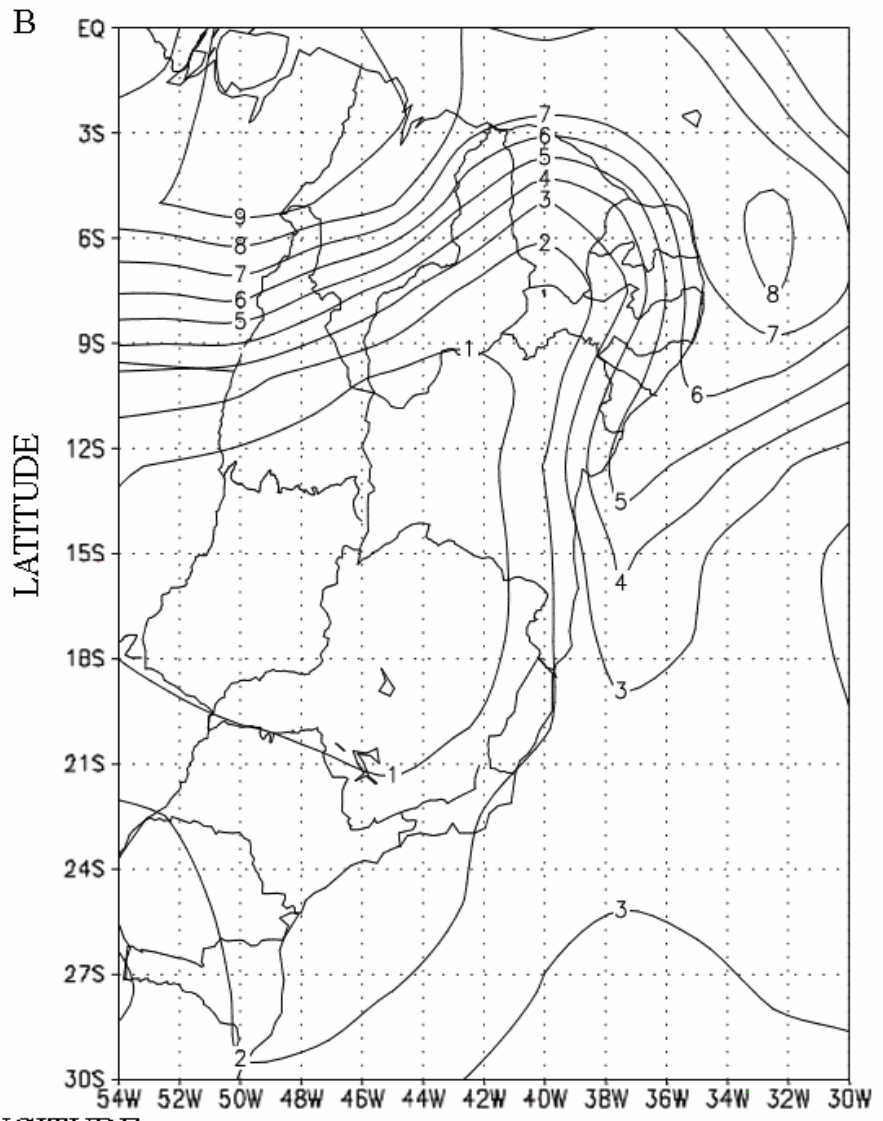

LONGITUDE

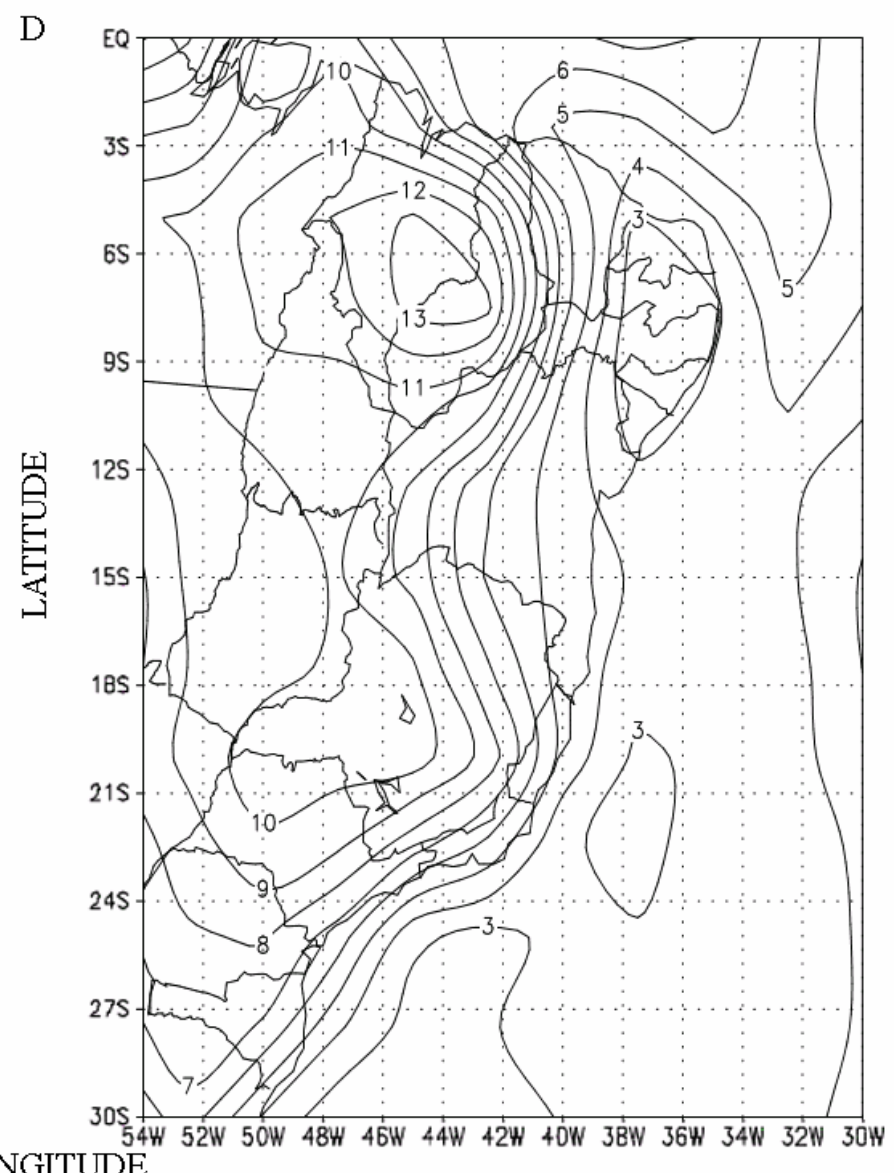

D LONGITUDE
C

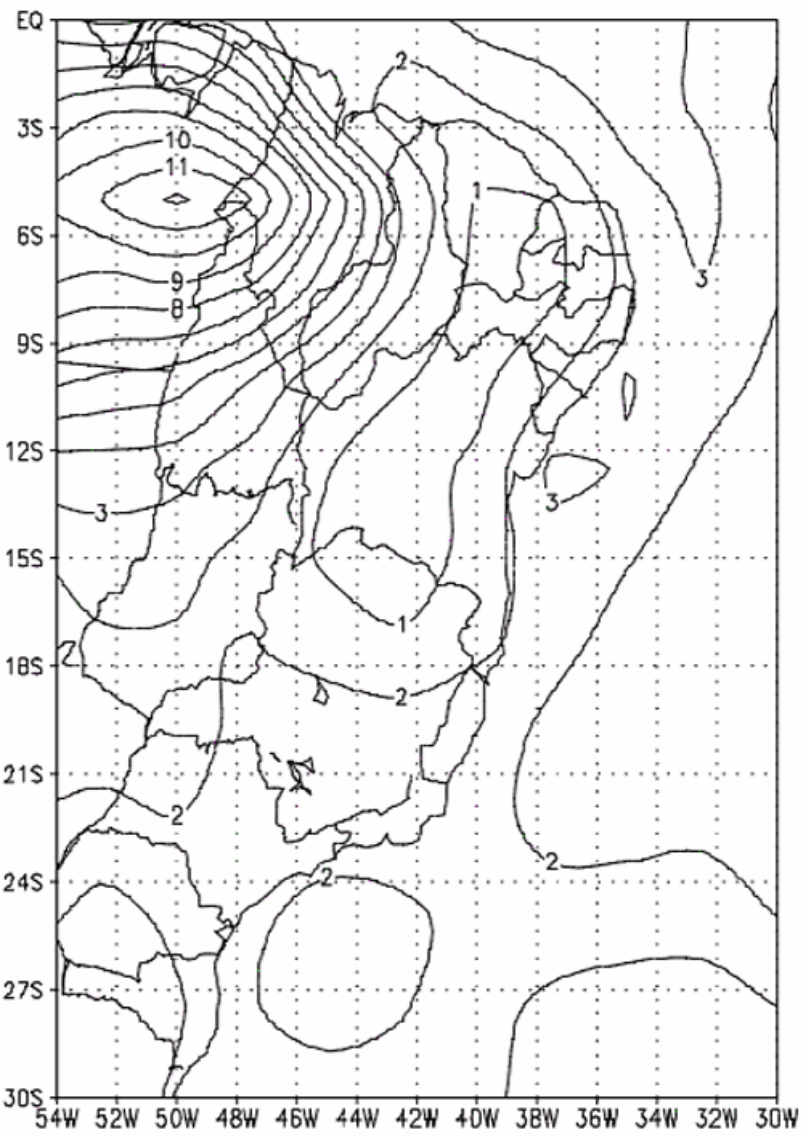

Figura 3. Taxa média de precipitação $\left(\mathrm{mm} \mathrm{d}^{-1}\right)$ para os meses: março $(\mathrm{A})$, junho (B), setembro (C), dezembro (D) 
gião NEB, de forma que no mês de março (mais chuvoso), os valores obtidos se apresentam maiores que para o mês de dezembro, e maiores ainda com relação aos meses de setembro e junho.

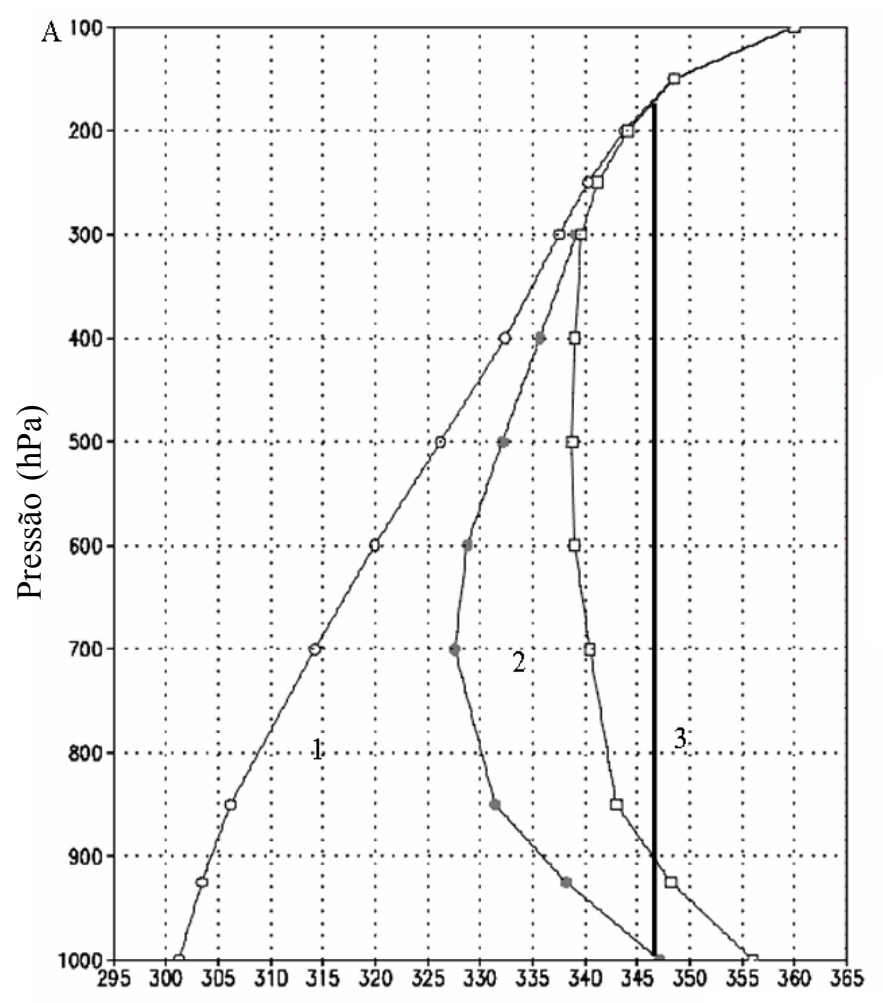

É possível verificar-se a instabilidade condicional atmosférica, através da variação vertical da energia estática úmida de saturação (a instabilidade se dará sempre que $\partial \mathrm{h}_{\mathrm{s}} / \partial \mathrm{z}<0$ ). Com base neste fato, verifica-se que a atmosfera sobre o NEB nos

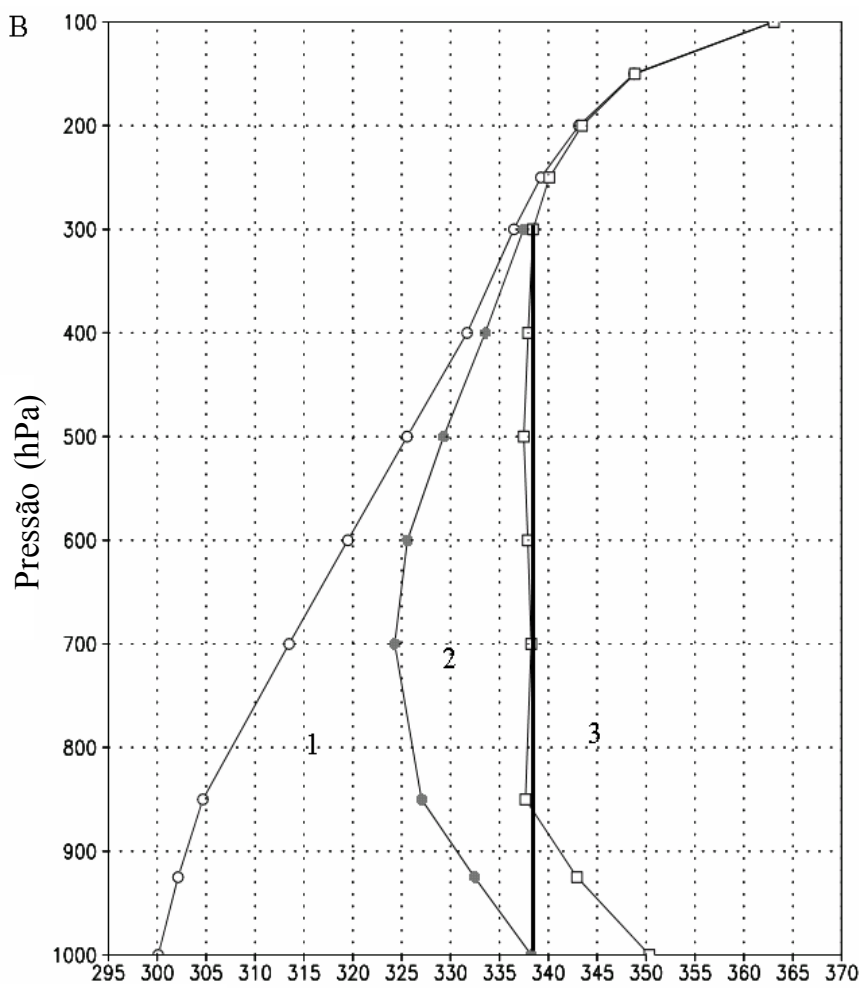

Energia estática

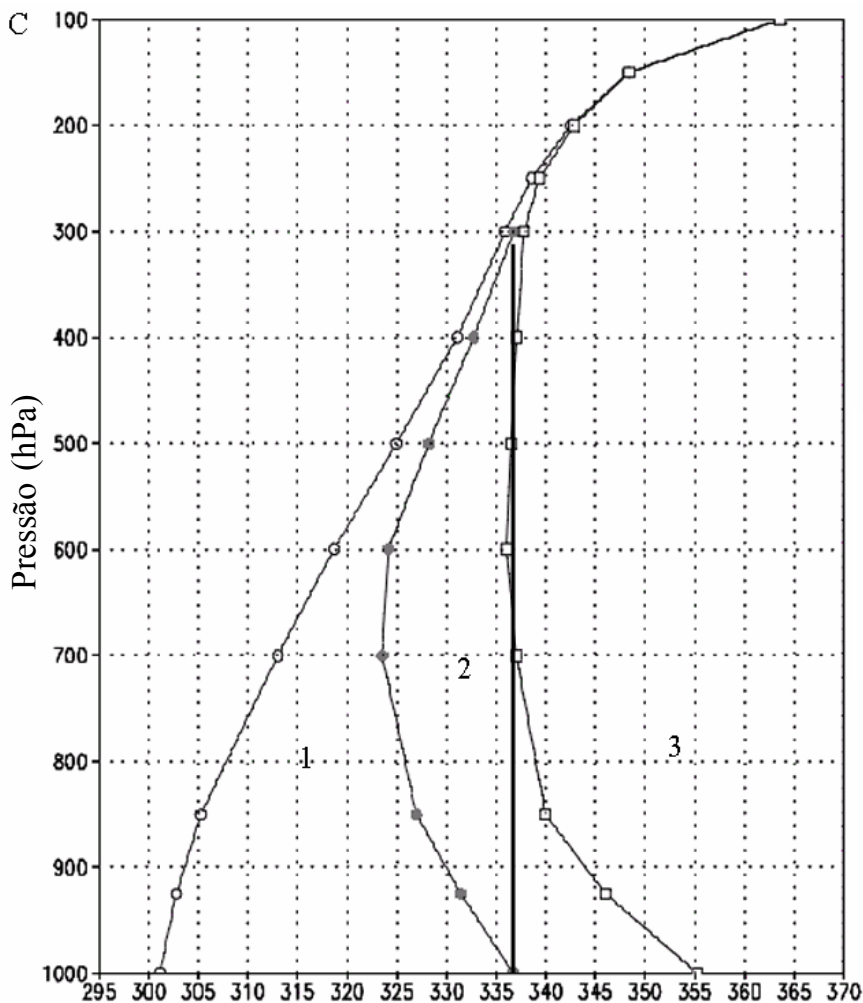

Figura 4. Distribuição vertical média das energias estáticas seca $\left(\mathrm{kJ} \mathrm{kg}^{-1}\right)$ (1), úmida (2) e saturada (3) sobre o NEB para os meses de: março (A), junho (B), setembro (C), dezembro (D) 
níveis abaixo de $700 \mathrm{hPa}$ se apresenta condicionalmente instável, enquanto para os níveis acima de $700 \mathrm{hPa}$, se encontra estável em todos os meses estudados.

A simples verificação da presença de instabilidade condicional não diz muita coisa a respeito da formação de nuvens convectivas. Parcelas em ascensão, na ausência de mistura, tendem a conservar a energia estática úmida do seu nível de origem que, geralmente, é o nível mais próximo ao solo (Williams \& Rennó, 1993). Para os quatro casos, o caminho de uma parcela em ascensão é indicado por uma linha vertical nas Figuras 4A a 4D. A área formada pela integração vertical da diferença entre a energia da parcela (linha vertical) e a curva de energia estática de saturação do ambiente, é proporcional à energia potencial convectiva (quando a curva da parcela está à direita da curva de $\mathrm{h}_{\mathrm{s}}$ ) e a energia de inibição convectiva (quando a curva da parcela está à esquerda da curva de $\mathrm{h}_{\mathrm{s}}$ ). A energia de inibição convectiva significa o quanto de trabalho externo deve ser realizado sobre uma parcela para torná-la flutuante. Evidentemente que, quanto maior for a energia de inibição, menor a possibilidade de formação de nuvens convectivas.

A simples análise das Figuras 4A a 4D mostra que os meses de junho (Figura 4B) e de setembro (Figura 4C) apresentam muita energia de inibição e quase nenhuma energia potencial convectiva, explicando a pouca precipitação observada nesses meses na maior parte do NEB. Por outro lado, os meses de março (Figura 4A) e dezembro (Figura 4D) mostram uma área de energia potencial convectiva muito maior que a de inibição convectiva o que, associado à convergência de massa em baixos níveis (Figuras 2A e 2D) que deve realizar o trabalho necessário para vencer a inibição convectiva, explica por que os meses de dezembro e março são mais chuvosos.

Para que se compreenda melhor o que acontece mês-amês, a Figura 5 representa a variação sazonal média sobre o NEB entre a diferença da energia estática úmida saturada e a energia estática úmida em função da altitude $\mathrm{h}_{\mathrm{s}}-h$ (área sombreada) assim como a variação sazonal

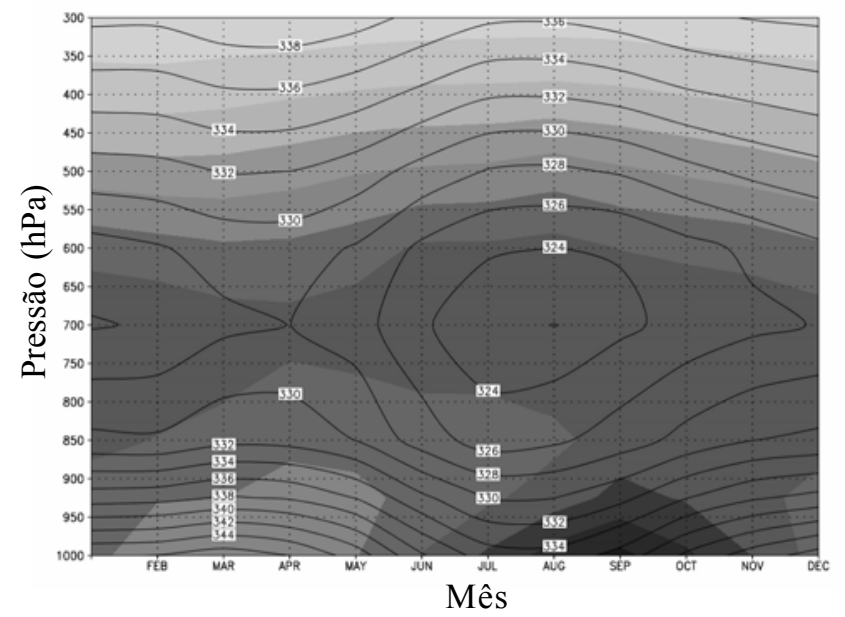

Figura 5. Variação sazonal média sobre o NEB da diferença entre a energia estática úmida saturada $\left(\mathrm{kJ} \mathrm{kg}^{-1}\right)$ e a energia estática úmida $\left(\mathrm{kJ} \mathrm{kg}^{-1}\right)$ com a altitude (sombreada) e variação sazonal média de energia estática úmida (h) com a altitude (isolinhas)

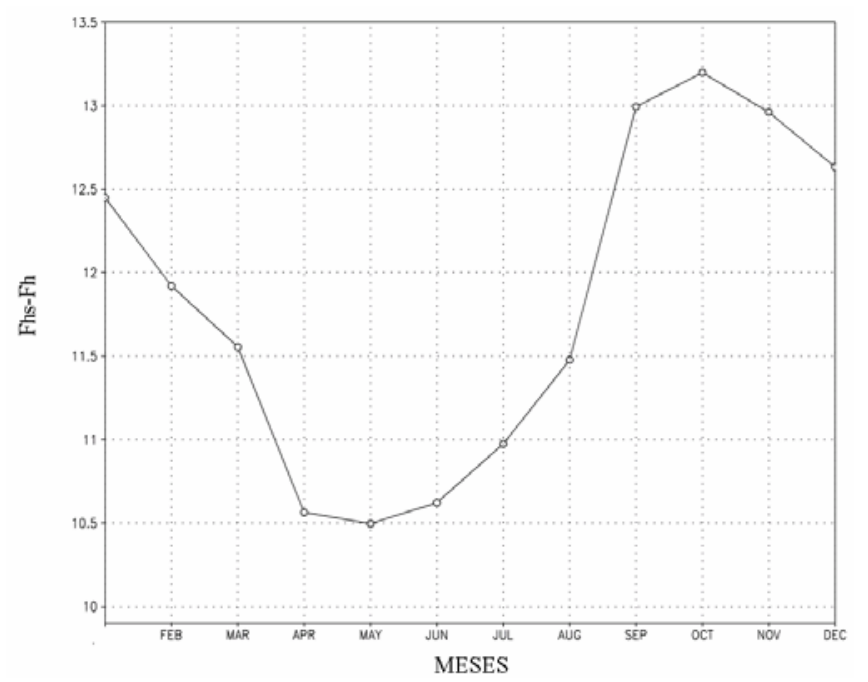

Figura 6. Variação sazonal média sobre o NEB da diferença entre a energia estática úmida saturada $\left(\mathrm{kJ} \mathrm{kg}^{-1}\right)$ e a energia estática úmida $\left(\mathrm{kJ} \mathrm{kg}^{-1}\right)$ em $850 \mathrm{hPa}$

de energia estática úmida em função da altitude $\mathrm{h}(\mathrm{z})$ (isolinhas), em kJ kg-1. Quando se comparam os valores obtidos entre os meses em estudo, verifica-se que entre 1000 e $850 \mathrm{hPa}$, o mês de março apresenta valores menores que setembro, significando que no mês de março a atmosfera está mais próxima da saturação que no mês de setembro. Para os níveis acima de $600 \mathrm{hPa}$, constata-se um gradiente vertical aproximadamente uniforme. Com relação à energia estática úmida, verifica-se que nos níveis abaixo de $800 \mathrm{hPa}$ o gradiente vertical está mais intenso e que existe um valor mínimo entre os meses de junho e setembro nos níveis médios.

Para destacar o comportamento dessa diferença, efetuouse um "corte" no nível de $850 \mathrm{hPa}$ (Figura 6). Observa-se que entre os meses de março e junho ocorrem os menores valores da diferença entre a energia estática saturada e a energia estática úmida e, para o mês de setembro, esta diferença é máxima, significando que a atmosfera no mês de março está mais úmida que no mês de setembro. Quanto menor essa diferença, menor a energia de inibição convectiva. Para formar nuvens convectivas em um mês como setembro, é necessária a atuação de um sistema dinâmico muito forte, como uma frente fria que atinja a região, ou um complexo convectivo de meso-escala, cuja força seja capaz de sobrepujar os efeitos inibidores ditados pela termodinâmica local. Esses sistemas ocorrem com alguma freqüência, mas, como são transientes, deixam pouco sinal na estrutura média da atmosfera.

\section{CONCLUSÕES}

1. A variação sazonal da ZCIT é refletida no transporte meridional de energia estática úmida, o que é um indicador da qualidade da estação chuvosa do semi-árido.

2. Em março existe convergência em baixos níveis sobre a região NEB, associada a movimento vertical ascendente, favorecendo a precipitação, enquanto nos meses de junho e setembro ocorrem divergências até o nível de $650 \mathrm{hPa}$, asso- 
ciadas ao movimento vertical descendente (subsidência), inibindo a precipitação.

3. A energia estática seca praticamente não apresenta diferença entre os meses estudados mas sim valores máximos nos baixos níveis da troposfera; entretanto, como é de se esperar, a energia estática úmida e a energia estática saturada apresentam valores maiores nos meses de março e dezembro, meses estes em que a atmosfera está mais úmida e, dentre eles, março é o mais úmido e mais próximo da saturação que os demais.

4. Verifica-se que a atmosfera se encontra instável abaixo de $700 \mathrm{hPa}$ e estável acima deste nível em todos os meses estudados, porém o que determina a possibilidade de convecção é a quantidade de energia de inibição convectiva.

\section{LITERATURA CONHECIDA}

Cavalcanti, E. P. Aspectos energéticos da atmosfera sobre o Nordeste do Brasil. Campina Grande: UFPB, 1986. 98p. Dissertação Mestrado.
Cavalcanti, E. P.; Gandu, A. W.; Azevedo, P. V. Transporte e balanço de vapor d'água atmosférico sobre o Nordeste do Brasil. Revista Brasileira de Meteorologia, São Paulo, v.17, n.2, p.207-217, 2002.

Kalnay, E. The NCEP/NCAR 40-year reanalysis project. Bulletin of the American Meteorological Society. Washington, v.77, n.3, p.437-471, 1996.

Marques, V. S.; Rao, V. B.; Molion, L. C. B. Interannual and seasonal variation in the structure and energetic of the atmosphere over Northeast Brazil. Tellus 35A. p.36-148, 1983.

Molion, L. C. B.; Bernardo, S. O. Dinâmica das chuvas no Nordeste brasileiro. In Congresso Brasileiro de Meteorologia, 11, Fortaleza: SBM 2000. p.561-572

Rao, V. B.; Brito, J. I. B. Interannual variations of rainfall in Northeast Brazil and their connections with the large scale features. In: WMO Symposion on Tropical Droughts, 2, Fortaleza. Resumos. .. Fortaleza, 1984. p.24-88

Rao, V. B.; Chapa, S. R.; Cavalcanti, I. F. A. Moisture budget in the tropics and the Walker circulation. Journal of Geophyssical Research, Washignton, v.103, p.13713-13728, 1998.

Strang, D. M. G. Análise climatológica das normais pluviométricas do Nordeste do Brasil. São José dos Campos: CTA/IAE, 1972.p.35

Williams, E.; Rennó, N. An analysis of the conditional instability of the tropical atmosphere. Monthly Weather Review, Boston, v.121, n.15, p.21-36, 1993. 